\title{
RITUALIDAD Y EXTRACTIVISMO. LA LIMPIA DE \\ CANALES Y LAS DISPUTAS POR EL AGUA EN EL SALAR DE ATACAMA-NORTE DE CHILE
}

\author{
Paola Bolados García ${ }^{1}$ y Sally Babidge ${ }^{2}$
}

\begin{abstract}
Resumen
En un contexto de progresiva privatización del agua llevada adelante por el régimen militar en Chile a partir del Código de Aguas de 1981, analizamos las disputas por el agua entre comunidades atacameñas del sur del salar de Atacama en el norte de Chile y las mineras, con las cuales ellas confrontan pero también negocian significados y valores. Desde una perspectiva etnográfica y retomando los aportes de la ecología política, la antropología de la naturaleza y los recientes trabajos sobre extractivismo, observamos las relaciones y tensiones entre significados cosmológicos, económicos y politicos del agua. Mapeando las recientes contestaciones por el agua, nos centramos en la "limpia de canales" en las comunidades atacameñas de Camary Peine, como un ritual multivalente y plurivocal, donde la complejidad de factores políticos, culturales y económicos se configuran en un entramado central de las relaciones sociales del agua.
\end{abstract}

Palabras claves: Atacameños - minería - agua - ritualidad y extractivismo.

\begin{abstract}
In the context of progressive privatization of water since the military regime in Chile and beginning with the Water Code of

1981, we analyze water disputes among Atacameño соттиnities of the Salar de Atacama and mining corporations whom they confront and also negotiate value and meanings. From an ethnographic perspective as well as taking up material from political ecology, the anthropology of nature, and recent work on extractivism, we observe the relations and tensions between cosmological, economic, and political meanings of water. Mapping the recent contestations over water, we focus on the 'limpia de canales' in the Atacameño communities of Camary Peine as a multivalent and plurivocal ritual, where complex political, cultural, and economic factors configure the central fabric of water social relations. Keywords: Atacameños - mining - water - rituality and extractivism.
\end{abstract} Recibido: mayo 2015. Aceptado: enero 2016.

\section{* InTRoducción}

En el último período, las disputas por el agua han dado origen a una robusta literatura que ha ganado terreno y adeptos en distintas regiones y áreas disciplinarias. En particular, se ha constituido en un núcleo de debate contencioso tanto en las ciencias sociales, como en las ciencias del medioambiente y la historia de las tecnologías. Las tensiones entre políticas del agua, usos culturales comunitarios y examinaciones respecto a los efectos del cambio climático, lo han convertido en uno de los temas académicos más relevantes de las últimas décadas. No obstante, parte importante de esta literatura ha insistido en relevar las dimensiones técnicas o jurídicas del agua, invisibilizando o deslegitimando sus dimensiones identitarias y sociohistóricas. Esto principalmente se explica por la judicialización de los conflictos en el ámbito de los derechos económicos que han entrado en pugna con los derechos culturales reconocidos a nivel global a partir de la década de los años noventa. Paralelamente y también a nivel global, promovido por organismos internacionales como el Banco Mundial, que consagran el agua como un recurso preponderantemente económico, se ha impuesto un discurso que releva una perspectiva tecnificada y burocratizada del agua. En particular estas lecturas se han legitimado como una narrativa global y dominante y que actualmente se ha canalizado a través de lo que se conoce como la Estrategia Integral de la Gestión Hídrica (en inglés conocida como IWRM, Integrated Water Resource Management). Esta política del agua global ha tensionado las relaciones, regímenes y sistemas de compresiones

1 Académica del Instituto de Historia y Ciencias Sociales. Convenio de Desempeño de las Humanidades, Artes y Ciencias Sociales de la Universidad de Valparaíso. Dirección Postal: Blanco 1215, oficina 101, Valparaíso, CHILE. Email: paola.bolados@uv.cl

2 Senior Lecturer, Anthropology, School of Social Science, University of Queensland, AUSTRALIA.Email: s.babidge@uq.edu.au

No 54 / 2017, pp. 201-216

EstUdios ATACAMEÑOS

Arqueología y Antropología Surandinas 
del agua entre actores, en particular en ámbitos como sus valores, equidad, acceso, distribución y sistemas de conocimientos (Orlove y Caton 2010: 404). En este sentido, y observando que las disputas han crecido y se han agudizado, relevamos las comprensiones antropológicas del agua, destacando su capacidad de conectar ámbitos de la realidad social, y un lugar donde fluyen a su vez y simultáneamente valores y usos culturales y económicos distintos.

La limpia de canales, como una de las actividades centrales de los trabajos de irrigación que realizan cada año las comunidades andinas -entre ellas la atacameña-, se constituye en este sentido simultáneamente, en una actividad comunitaria política e identitaria que reafirma las formas de pertenencia a la comunidad, a la vez en un espacio social donde -incluso en situaciones de subordinación y asimetría - negocian el control del agua y la tierra en un contexto de extractivismo minero. Como recogen los trabajos relacionados a la festividad en el contexto andino, la limpia se inscribe en una cosmovisión que prefigura la propiedad del agua relacionada con su uso en un contexto de obligaciones y derechos comunitarios y ancestrales (Cuadra 2000; Yáñez y Molina 2011, 2008). Paralelamente, ésta representa un ritual de legitimación étnica y política en un contexto de creciente demanda de sus recursos naturales y culturales que disputa territorio y recursos con industrias globales como la minería y el turismo en las últimas dos décadas (Bolados 2014a y b). En este marco de complejidades intra comunitarias y de conflictos extra comunitarios, la limpia de canales -como la principal actividad- en torno al agua que se festeja hoy en el salar de Atacama, representa un acceso indispensable en la comprensión de la problemática y de las formas de resolución de las disputas por el agua. En este trabajo, analizamos las tensiones que esta práctica del manejo del agua genera en un contexto de neoliberalización de la naturaleza y las estrategias de regulación que se expresan en la festividad de la limpia de canales entre los diversos agentes involucrados. ${ }^{3}$ En particular, centramos nuestro

3 Este artículo se nutre de dos investigaciones realizadas en períodos paralelos en el salar de Atacama: la primera investigación dirigida por la académica Paola Bolados de la Universidad de Valparaíso-Chile, se centra en los impactos de la minería y el turismo en el salar de Atacama. Ésta tuvo como objetivos historiar y cartografiar los impactos de la minería y el turismo en el salar de Atacama. El trabajo de campo se centró en dos localidades: el estudio sobre los impactos de la minería se centró en la comuni- interés en analizar cómo en un contexto de privatización y transnacionalización del agua como recurso fundamental para el desarrollo minero del salar, las comunidades a través de la ritualidad buscan legitimar su pertenencia al territorio mientras también negocian valorizaciones del agua como un recurso económico que mejore las condiciones de vida de sus comunidades.

Nos aproximamos a las disputas por el agua en el salar de Atacama principalmente desde lo que se conoce como la antropología ambiental y de la naturaleza, la ecología política y los trabajos recientes sobre extractivismo. La antropología ambiental y de la naturaleza nos permite pensar las relaciones entre naturaleza y cultura más allá del campo dicotómico en el que han estado circunscritas. En particular, una epistemología occidental que com-

dad de Cámar en un contexto de negociaciones y conflictos de la comunidad con la empresa SQM, principal exportadora del litio y que tiene sus pozos extractivos en territorios demandados por la comunidad. En tanto, los estudios de los impactos del turismo se centraron en la localidad de San Pedro de Atacama. En el caso de Camar, la etnografía significó la participación durante un año (enero 2013 a enero 2014) en las principales actividades y festividades (carnaval en febrero, fiesta patronal el día de San Antonio el 16 de junio y la limpia de canales realizada en septiembre del año 2013). El trabajo cartográfico significó relevar la documentación secundaria de informes de organismos del Estado y mineras a mapas para visualizar la cantidad de empresas mineras existentes, los derechos de aguas vigentes, los sectores protegidos por legislaciones nacionales e internacionales y los sectores que habían sido adjudicados para la exploración geotérmica. La segunda investigación que nutre este artículo, es la que dirigió en igual período la académica Sally Babidge de la Universidad de Queensland-Australia. Su trabajo examina las interacciones y negociaciones entre empresas mineras y pueblos indígenas alrededor del salar de Atacama. El estudio se centra en los efectos socioculturales de la industria minera en el pueblo atacameño de Peine, en cuyo territorio están situados los pozos extractivos de aguas subterráneas de Minera Escondida Limitada (MEL), operada por BHP Billiton (de origen australiano). La investigación etnográfica emprendida desde el año 2010, con terrenos anuales o bianuales a la región (la más larga en 2011 de cuatro meses y medio, la más corta de tres semanas, con trece meses totales en terreno hasta fines de 2015), involucró la participación en eventos sociales, rituales y comunales (como la limpia de canales), y prácticas cotidianas de regadío, agricultura y pastorales, como también la observación de reuniones de la comunidad, y las realizadas entre ellas y las empresas mineras y/o servicios del Estado. También en el marco de esta investigación entrevistamos a dirigentes de los otros pueblos del salar (Socaire, Camar, Talabre y San Pedro de Atacama). 
partimenta y organiza las relaciones y categorías de maneras excluyentes y dicotómicas. En este sentido, estas perspectivas pretenden superar las miradas deterministas del medio ambiente, así como también las que solo se sustentan en dimensiones simbólicas que atraviesan la relación entre naturaleza y cultura. En la perspectiva de la antropología de la naturaleza de Descola y Pálsson (2001), la idea de mutualismo contribuye a mostrar una nueva perspectiva ecológica interespecies que conforman una cosmología compartida entre seres humanos y no humanos. Asimismo, sus aportes han contribuido en desnaturalizar la naturaleza reafirmándola como una construcción social.

En esta misma perspectiva, la ecología política ha tenido un desarrollo relevante en el último período, en particular incorporando las asimetrías del poder que se encuentran en las relaciones entre naturaleza y cultura. Éstas se constituyen en un aspecto central para comprender las significaciones tanto simbólicas como materiales que las comunidades le dan al agua como un bien cultural, social, político, ritual y económico (Carrasco 2016; Prieto 2014; Budds 2013; Orlove y Caton 2010 y Strang 2004). Inspirados en la tradición antropológica de Mauss (1990), estos trabajos muestran cómo el agua puede verse como un "hecho social total", en donde usos, políticas y regímenes de agua, se conjugan y confluyen con nociones del agua en tanto bienes y recursos económicos legítimos. Como señala Strang, las significaciones del agua no están impuestas desde la distancia; por el contrario, son los resultados de interacciones vitales de las personas con el agua, una relación en que "la naturaleza y la cultura literalmente fluyen una dentro de la otra” (Strang 2004: 3). La autora sostiene que la gestión de recursos naturales es crítica en la mantención de un sentido de comunidad y el sentimiento de identidad en común. Es decir, el significado de agua está en el nexo entre cultura y naturaleza, el cual es mediado por la experiencia de las personas y las comunidades. Es decir, el control del agua siempre ha tenido un significado en tanto poder social, económico y político, sosteniendo que el agua es "un barómetro que indica la medida en que identidad, poder y recursos están compartidas" (Strang 2004: 21).

En ese sentido, las disputas así como las negociaciones en torno al agua, requieren ser analizadas en una perspectiva que incorpore las múltiples dimensiones y esferas involucradas. Como expresa Carrasco en los casos etnográficos que trabaja en las comunidades atacameñas del Alto Loa, las comunidades

...tratan al agua como una mercancía cuando arriendan el agua a-, pero no cuando defienden el agua de- una compañía minera. Esto es aún más complejo por la economía moral de agua (Trawick 2001) que asigna a ésta singularidad o sacralidad. Esta moralidad es desplegada con especial fuerza en las prácticas rituales, tal como la ceremonia de la limpia de canales. Cada año el atacameño ofrece el pago de un tributo a la pachamama - Madre Tierra. De particular interés son la solidaridad social y la cooperación por las cuales los miembros de la comunidad se comprometen con su trabajo como intercambio con las fuerzas de la naturaleza. El tan antiguo ritual ha sido performado por la comunidad, la madre tierra proveerá cada año abundancia. A la vez, el objetivo económico orientado a las comunidades indígenas atacameñas, presionan a ellas a girar lo sagrado en lo profano en sus luchas por el agua en los Andes chilenos (Carrasco 2016: en prensa). ${ }^{4}$

En este sentido Carrasco, aunque refuerza la idea de choque entre visiones y usos del agua, también releva el carácter performativo en el cual operan lógicas culturales distintas que compiten y se incorporan en una lógica de intercambios entre comunidades y mineras. En esa competencia de lógicas culturales, aunque en condiciones asimétricas, los intercambios y reciprocidades sagradas y mercantilizadas del agua recorren variadas trayectorias y biografías en torno a ella, configurándose en el centro de las disputas y negociaciones actuales. Esas biografías históricas han pasado momentos diversos como lo demuestra en sus tesis Prieto (2014), donde ha señalado cómo la participación del Estado en la inscripción de derechos de aguas favoreció una naturalización del sistema de riego, desconociéndolo como un logro tecnológico de la comunidad de Chiu Chiu para mantener sus cultivos activos (Prieto 2014: 85-92). Como el autor lo releva, las comunidades han sido activas en sus relaciones con la minería y el Estado respecto a sus derechos sobre el territorio y sus recursos. 5 Como sostienen Orlove y Caton, y basándose en los trabajos de Lansing y una numerosa

\footnotetext{
4 La traducción es nuestra.

5 Demuestra que ya en 1960, el pueblo de Toconce llamó a manifestaciones en contra de asignaciones de agua por parte del gobierno y formó un grupo que se llamó 'central de los pueblos precordilleranos' para organizarse y protestar en Calama (Prieto 2014: 139-40).
} 
literatura, rituales como la limpia de canales funcionan no solo como prácticas de irrigación, sino a la vez, en otras esferas del dominio económico, social y político. Debido a sus características principales, tales como la conectividad y materialidad, el agua puede también y al mismo tiempo, constituir un marcador del territorio y una frontera políticamente cargada, a la vez que un régimen de intercambio que legitima, anula o reconstituye relaciones sociales en un contexto de sacralidad (Orlove y Caton 2010: 405).

En tercer lugar, los trabajos sobre extractivismo, nos permiten comprender por qué una economía históricamente inserta en la vida de los atacameños del salar como es la minería, se vuelve más conflictiva en el último período. Esto en particular, a partir del proceso de expansión de la minería global en la década de los años noventa, en un contexto de los desiertos más áridos del mundo y uno de los lugares donde se concentran humedales, vegas, bofedales, salares, lagunas y otros sitios de importancia para la obtención de agua en el Norte Grande en Chile. Como sostiene Gudynas (2012), en la última década, gobiernos tanto conservadores y progresistas de la región latinoamericana, continuaron una política extractivista con el fin de expandir y consolidar sus economías. En el mismo sentido, Svampa y Antonelli señalan que la década de los años noventa se caracteriza entre otras cosas, por las reformas a los marcos regulatorios orientados a facilitar la actividad extractiva de las grandes empresas transnacionales. Éstas afectarán directamente a los recursos considerados no renovables como el agua y revelarán nuevos cambios en la organización de las relaciones entre Estados nacionales y corporaciones transnacionales (Sawyer y Gómez 2012). La minería en este sentido y en este período se consagra en una verdadera política de Estado (Svampa y Antonelli 2010, Sawyer y Gómez 2012), la cual paradójicamente correrá a la par de políticas multiculturales, patrimoniales y ambientales dirigidas a reconocer y proteger los derechos de los pueblos indígenas, entre ellos principalmente las tierras y las aguas. Como sostienen algunos autores, la legislación ambiental inaugurada en Chile a comienzos de los años 1990, responde a un intento de compatibilizar las presiones de las organizaciones sociales y las demandas del mercado, en un contexto de regulaciones impuestas por los tratados de libre comercio y las pretensiones de Chile para entrar a la Organización para la Cooperación y el Desarrollo Económicos, OCDE (Tecklin et al. 2011).
No obstante, estas medidas comenzaron a ser contestadas por múltiples comunidades y organizaciones que cuestionaron los alcances y efectividad de las legislaciones culturales y territoriales impulsadas por las políticas democratizadoras de los años 1990 en la región latinoamericana (Merlinsky 2013; Zhouri 2012). Esto se expresó con mayor ahínco en el salar de Atacama a partir de las disputas suscitadas con el proyecto Pampa Colorada, una vez que Minera Escondida Limitada (MEL, controlada por la australiana BHP Billiton) solicitara la aprobación para la extracción de más de mil litros por segundo de aguas subterráneas en áreas demandadas por las comunidades y también protegidas por el Estado a través de los decretos del 2003 y 2006 sobre protección de vegas y bofedales de la Dirección General de Aguas. Como veremos, los últimos 10 años de relaciones y negociaciones entre la minera y algunas comunidades del salar a través de convenios y acciones de responsabilidad social, no fueron suficientes para contener las tensiones que estallaron en el 2007, una vez que las comunidades comprendieron que la expansión minera nacional y trasnacional en su territorio progresivamente exponía "la sustentabilidad" a partir de la disminución radical del agua para las actividades tradicionales como la agricultura, el pastoreo y más recientemente el turismo.

\section{* Cosmovisión, política y eCONomía del AGUA EN EL SALAR DE ATACAMA}

Los habitantes del salar de Atacama (Figura 1), habitada por comunidades indígenas atacameñas y desde los años noventa - producto del boom turístico- por una importante población de no atacameños (denominados afuerinos), enfrenta en las últimas décadas presiones sin precedentes en relación al acceso y disponibilidad del agua. Esto debido principalmente a la demanda creciente de agua por parte de la industria minera (Aldunate 1985; Yáñez y Molina 2011; Barros 2009). Una industria que el 2012 alcanzó a representar en términos nacionales alrededor del 20\% del Producto Interno Bruto, PIB, convirtiéndola en la tercera fuerza económica del país (Cochilco 2010). ${ }^{6} \mathrm{La}$ demanda de la minería tanto metálica como no

\footnotetext{
6 Estos datos en el último año han experimentado cambios relevantes una vez que el precio del cobre alcanzó sus niveles más bajos. Por otro lado, la minería ha experimentado en Chile este último período una severa crítica, conociéndose sus relaciones con el financiamiento de la política a partir de dos casos vinculados con
} 


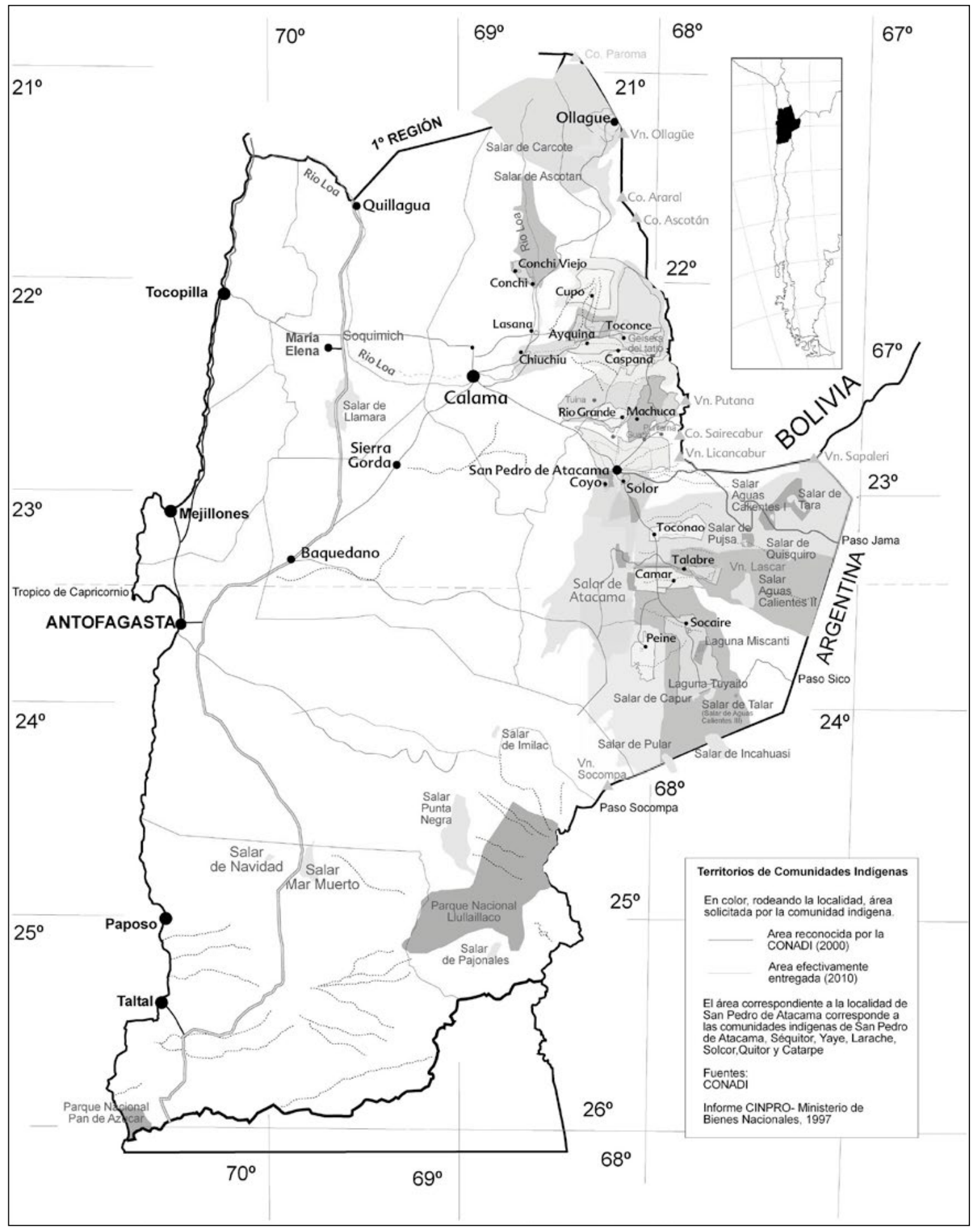

Figura 1. 
metálica -que lo posicionan entre los principales países exportadores a nivel mundial- representa aproximadamente un 96\% del consumo energético de la región de Antofagasta, cuyos dos tercios de su territorio están "concesionados" para actividades de exploración y explotación minera (Sernageomin 2010). Aunque gran parte de esta actividad se concentra en el desierto intermedio de la región, su desarrollo y expansión ha dependido del agua de la precordillera, la cual durante gran parte del siglo XX se vio sometida a una excesiva explotación, principalmente por parte del Estado chileno a través de dos empresas: la minera estatal de cobre Codelco y la hasta ese momento empresa sanitaria de servicios de agua potable ESSAN. La década de los años noventa finaliza con la declaración del río Loa como "agotado". No obstante, el salar de Atacama comienza a experimentar transformaciones relevantes en términos de la disponibilidad de agua, con la actividad extractiva minera no metálica asociada al litio y la adquisición de derechos de aguas subterráneas para la expansión de la minería metálica cuprífera.

La exploración del litio parte muy tentativamente en la década de los años 1960, pero se intensifica e inicia actividades extractivas desde la década de 1980, bajo una legislación impuesta por la dictadura militar de Augusto Pinochet. En particular, el Código de Aguas del año 1981 y el Código Minero del año 1982, serán las dos herramientas legales necesarias para legitimar un proceso de privatización creciente y sostenida de los recursos naturales en Chile. Como sostiene Budds en sus estudios sobre Chile, la relación agua y poder es central para comprender las medidas económicas asumidas en Chile. Las implicancias de neoliberalizar la naturaleza configurarían un nuevo campo de disputas y juegos, los cuales abrieron nuevos mercados que fueron posibles solo gracias a las alianzas políticas que el neoliberalismo exigió (Budds 2013: 303). Estos códigos tendrán fuerza jurídica en el Decreto 600 de inversión directa extranjera (EID)

\footnotetext{
la minera SQM. En tercer y último lugar, las adjudicaciones de exploración geotérmica realizadas por el gobierno de Sebastián Piñera (2010-2014) y sin conocimiento de las comunidades locales donde estos proyectos se desarrollarían, significaron una judicialización de los proyectos energéticos orientados a abastecer la actividad minera, generándose a nivel nacional un temor en el empresariado por la huida de las inversiones producto del rechazo de las comunidades y los elevados costos energéticos en el país. Todos estos factores se encuentran actualmente en pleno desarrollo y en el centro del debate nacional.
}

que favorece la entrada de capitales transnacionales y la Constitución del año 1981 que consagra la propiedad privada. Ambos serán la plataforma jurídica indispensable para descomponer el régimen de tenencia de la tierra indígena. Se inicia así un proceso de "concesión" de derechos mineros y privatización de las aguas subterráneas, en particular hacia tres empresas que iniciaron operaciones en ese período en el área del salar de Atacama: la primera empresa en instalarse en el lugar será Soquimich (actualmente SQM), cuya privatización quedará en las manos de la familia de Augusto Pinochet; MEL (ya mencionada arriba); y en tercer lugar, Minera Zaldívar actualmente controlada por Antofagasta Minerals (de la familia Luksic). Minera Escondida Limitada -MEL-, hoy la segunda productora minera de cobre en Chile después de Codelco, comienza sus operaciones a fines de los años ochenta realizando sus primeras solicitudes de derechos de aguas bajo el nombre de Minera UTAH, la cual en los años 1990 cambia de nombre a Minera Escondida, convirtiéndose al año 2012 en la controladora de las aguas subterráneas en el salar de Atacama. En total y desde los primeros derechos otorgados en 1987 hasta los más recientes, suman 1710 litros por segundo, configurándose como la empresa con mayor cantidad de litros asignados según el Informe de la Dirección General de Aguas del 2012 (Figura 2). En síntesis, las aguas del salar se encontrarán monopolizadas por dos empresas transnacionales (MEL y Barrick), y una tercera (SQM), que aunque se muestra "nacional" y dedicada a fertilizantes, representa junto a Rockwood Lithium (actualmente en manos norteamericanas), las dos empresas controladoras a nivel internacional de la producción y comercialización del litio y sus subproductos.

Pese a que Chile vivió las últimas cuatro décadas bajo el imaginario del "milagro económico" con un crecimiento económico que superó el 6\% hacia fines de los años ochenta y parte de los años noventa a causa de un extractivismo ilimitado de los recursos naturales (Silva 1996), los inicios de siglo XXI mostraron un agotamiento y disconformidad del modelo extractivista minero, así como revelaron las limitaciones e insuficiencias legales de las protecciones nacionales e internacionales relacionadas con los derechos indígenas, patrimoniales y ambientales que se propagaron en ese período.? Se inició así, un proceso de movilizaciones

7 El salar de Atacama tiene lugares protegidos por el Estado (sitios SNASPE) desde 1990. Principalmente la Reserva Nacional Los 


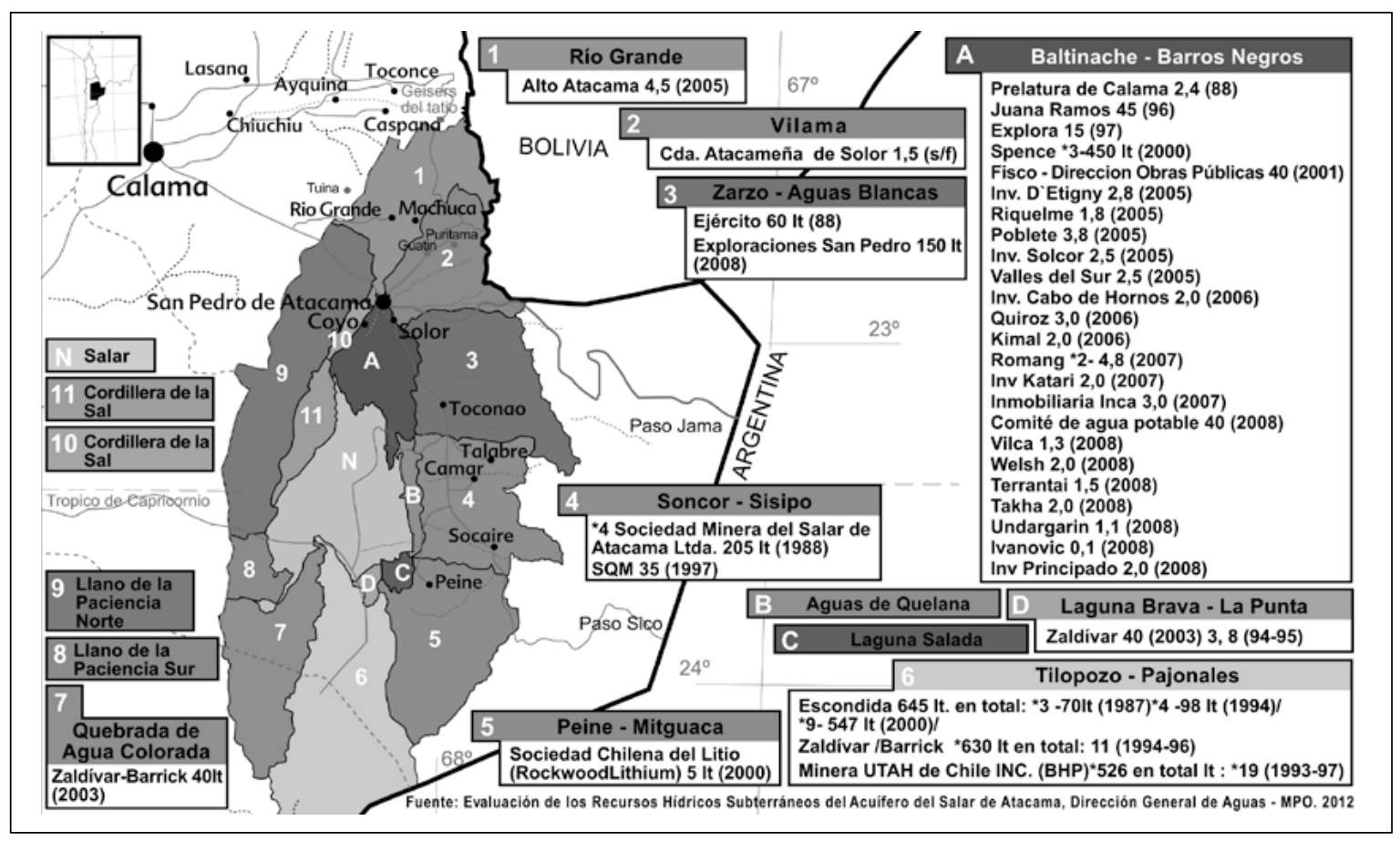

Figura 2.

de grupos y comunidades que pusieron en evidencia las externalidades negativas de esta industria, así como impusieron nuevas exigencias para su licenciamiento en los territorios donde esta actividad se desarrolla. Lo que se presenta como un elemento de desarrollo para la región y sus poblaciones, se configuró progresivamente en una actividad económica conflictiva en términos sociales y ambientales en los comienzos del presente siglo.

"David y Goliat": Una lucha desigual. Con la imagen bíblica de la lucha entre David y Goliat, el entonces presidente del Consejo de Pueblos Atacameños (quien lideró las movilizaciones contra el proyecto Pampa Colorada de Minera Escondida y luego los recursos judiciales contra el Estado por las adjudicaciones geotérmicas), definió la situación actual del salar. Una realidad cuya complejidad se explica en parte, por la coexistencia de legislaciones

Flamencos y las Lagunas Meñique y Miscanti; así como tres sitios protegidos como sitios RAMSAR que resguarda humedales de importancia mundial. El año 2002 es declarado zona ZOIT o Zona de Interés Turístico, protección bajo la cual las comunidades lograron frenar el proyecto de exploración geotérmica en el Tatio el año 2010. Paralelamente, la Dirección General de Aguas (DGA), dictó dos decretos de protección de vegas y bofedales en la región de Antofagasta los años 2003 y 2006. heterogéneas que defienden principios diversos y que se estructuran en forma jerárquica. Por un lado las bases legales impuestas durante el régimen cívico-militar destinadas a la actividad extractiva y exportadora (nos referimos a la Ley de inversión extranjera directa -Decreto 600- del año 1976, la Constitución del año 1980, el Código de Aguas año 1981 y el Código de Minería del año de 1982). Por otro, la nueva legislación indígena del año 1993, la legislación medioambiental del año 1994 yel Convenio 169 de la OIT, principal órgano internacional de defensa de los derechos indígenas ratificado por Chile el 2008. Pese a que estas legislaciones iban dirigidas a modificar y corregir sustancialmente los impactos de la política económica, éstas en definitiva no frenaron la entrega indiscriminada de derechos de aguas subterráneas, que continuaron otorgándose pese a las normas específicas de la propia Dirección General de Aguas (DGA) aprobadas el año 2003 y el 2006 referidas a la protección de las aguas de vegas y bofedales en la región de Tarapacá y la de Antofagasta (DGA 2004 y 2006). La Ley Indígena se mostró débil para defender los derechos que señala le dan sentido, sean estas la de proteger las tierras como las aguas, especialmente las de comunidades como 
la atacameña en el norte de Chile. ${ }^{8}$ La legislación indígena quedó así subordinada a lo establecido por el Código de Aguas del año 1981, estimulando un proceso de inscripción de aguas comunitarias mientras paralelamente sobreotorgaba derechos de aguas subterráneas bajo la lógica de propiedad privada consagrada en la Constitución de 1980.9 En tanto la legislación ambiental aprobada a solo un año de la Ley Indígena promulgaba la defensa del principio a vivir en un espacio libre de contaminación; no obstante en el artículo $1^{\circ}$ señala un alcance:

Art 1: El derecho a vivir en un medio ambiente libre de contaminación, la protección del medio ambiente, la preservación de la naturaleza y la conservación del patrimonio ambiental se regularán por las disposiciones de esta ley, sin perjuicio de lo que otras normas legales establezcan sobre la materia (el subrayado es nuestro. Ley 19.300/1994).

8 La Ley Indígena se refiere al tema de las aguas específicamente en el punto e) del artículo 26, que señala que las Áreas de Desarrollo Indígenas - ADI- deben considerar como elemento de definición su "Dependencia de recursos naturales para el equilibrio de estos territorios, tales como manejo de cuencas, ríos, riberas, flora y fauna". A su vez, en el artículo 39 se refiere a las responsabilidades de la CONADI en relación a la protección de las tierras y las aguas manifestando el deber de d) "asumir, cuando así se le solicite, la defensa jurídica de los indígenas y sus comunidades en conflictos sobre tierras y aguas y ejercer las funciones de conciliación y arbitraje de acuerdo a lo establecido en esta ley”; e) "velar por la protección de las tierras indígenas a través de los mecanismos que establece esta ley y posibilitar a los indígenas y sus comunidades el acceso y ampliación de sus tierras y aguas a través del Fondo respectivo"; $\mathrm{f}$ ) "promover la adecuada explotación de las tierras indígenas, velar por su equilibrio ecológico, por el desarrollo económico y social de sus habitantes a través del Fondo de Desarrollo Indígena.

9 En el párrafo 2 sobre "Disposiciones Particulares Complementarias para los Aimaras, Atacameños y demás Comunidades Indígenas del Norte del País" le otorga estatus de legitimidad a las "c) tierras patrimoniales de propiedad de varias Comunidades Indígenas tales como pastizales, bofedales, cerros, vegas y otras de uso del ganado auquénido". Asimismo, establece que: “Se deberá proteger especialmente las aguas de las comunidades Aimaras y Atacameñas. Serán considerados bienes de propiedad y uso de la Comunidad Indígena establecida por esta ley, las aguas que se encuentren en los terrenos de la comunidad, tales como los ríos, canales, acequias y vertientes, sin perjuicio de los derechos que terceros hayan inscrito de conformidad al Código General de Aguas" (Ley indígena, 1993. El subrayado es nuestro).
Como queda establecido en la frase "sin perjuicio de lo que otras normas legales establezcan sobre la materia", las legislaciones indígenas y medioambientales quedaron subordinadas a las otras leyes que son el soporte jurídico-institucional del modelo económico basado en exportaciones. De hecho, la ambigüedad de la Ley de Medio Ambiente exigió un reglamento que vino a hacerse efectivo recién el año 2001, lo cual implicó un retraso de casi 7 años para funcionar plenamente. A esta dificultad para su implementación y efectividad, se sumó el cuestionamiento al Sistema de Evaluación de Impacto Ambiental (SEIA) que estableció que el Estudio de Evaluación Ambiental (EIA) debe ser presentado por la empresa que ingresa el proyecto a evaluación. Estos informes dieron origen a un nuevo mercado: el de las consultorías cuyo objetivo - como nos dijo un ingeniero ambiental que trabaja en una de las empresas especializadas- es "satisfacer al cliente", señalando los problemas y las tensiones que se generaban en torno a la elaboración del informe. Junto a este elemento, la Ley de Medio Ambiente mostró contradicciones relevantes, como las que se refieren a la participación de las comunidades en la oposición a estos proyectos. Por una parte se critican los plazos exiguos que establece la ley para que las comunidades presenten sus oposiciones; del otro, el carácter consultivo y no decisivo de estas oposiciones, las que quedan finalmente en manos del Consejo de Ministros -órgano máximo que la ley consagra-, conformado por los ministerios vinculados al proyecto (en su mayoría participan Minería, Salud, Obras Públicas, Energía, Medio Ambiente).

En este contexto, la limpia de canales aparece como el ritual del agua por excelencia donde observar los nuevos significados de la identidad, el territorio y las relaciones sociales y económicas entre actores. Visto desde los procesos de etnicidad contemporáneos, la limpia se constituye en uno de los rituales emblemáticos de continuación de la costumbre indígena y manejo del agua frente a un modelo extractivista como el que ha desplegado el Estado de Chile en esta región, así como un recurso tanto cultural como económico relevante desde el cual las comunidades negocian su legitimidad y participación en las acciones y proyectos que se despliegan en la región del salar. Un proceso del cual tuvimos un primer estallido hace casi una década atrás, cuando el salar de Atacama fue protagonista de dos conflictos que tuvieron como epicentro el agua. Se trató del proyecto en Pampa Colora- 
da de la transnacional Minera Escondida que consideraba la extracción de más de mil litros de agua por segundo; y el segundo, frente al proyecto de exploración geotérmica a cargo del consorcio nacional/transnacional formado por las empresas Codelco y ENAP y la multinacional italiana ENEL (controladora del $80 \%$ de la producción energética en Chile), y cuyo impacto en el sitio turístico Géiseres del Tatio generó una oposición que trascendió a nivel internacional. Ambos conflictos reconfiguraron las relaciones entre comunidades, Estado y mineras, y en particular confirmaron que ni las funciones ni acciones de responsabilidad social asegurarían un escenario de licenciamiento social y ambiental para la expansión minera. Por el contrario, ambos conflictos mostraron que en torno a las visiones y usos del agua diversos, las comunidades atacameñas del salar buscaban legitimarse social y políticamente, a la vez que interlocutores reconocidos por el Estado y las empresas en las negociaciones económicas e intercambios en torno al territorio y sus recursos, entre ellos el agua (Bolados 2014a).

La limpia de canales en tanto ritual social y político, tuvo una reelaboración importante desde los conflictos suscitados el 2007 contra Minera Escondida y luego del Tatio el 2009. En particular, ambos conflictos plantearon una exigencia mayor para las mineras en cuanto a sus estrategias corporativas y formas de relaciones institucionalizadas con las comunidades. Particularmente aquellas establecidas a través de sus fundaciones y acciones de Responsabilidad Social Empresarial (RSE), cuya finalidad parecía inevitablemente amarrada a obtener licencia para expandir la industria. El conflicto del Tatio además reveló un aspecto invisibilizado de la problemática: que las externalidades negativas de una industria sobre otra no se perdonarían. En este caso, la industria turística se vio directamente amenazada por la industria minera a través de sus solicitudes de exploración geotérmica en el principal destino turístico de la región en los Géiseres del Tatio. Las relaciones se tensionaron durante este período de manera notoria, generando un clima de desconfianza y enemistad que tardó en limarse. Especialmente una vez que luego de lo ocurrido con el Tatio se observara el interés ya no solo por las aguas subterráneas, sino de otro potencial energético utilizado como las energías no convencionales, como es el caso de la geotermia. Con el Tatio, lo que se estaba prefigurando era la viabilidad de exploración y explotación de esta fuente de energía, la cual además ostenta el rótulo de "energía limpia". En 2010 las comunidades toman conocimiento de múltiples adjudicaciones geotérmicas en toda la precordillera. Luego el 2011 aparecen nuevas adjudicaciones en sitios protegidos como Pular y Aguas Calientes, originando movilizaciones entre las comunidades, las que se canalizaron esta vez a través de vías judiciales. Los cuestionamientos centrales eran dos: la Ley de Geotermia faculta a quien tiene concesión el uso de los otros recursos existentes como la tierra, los minerales y el agua existentes en esa concesión. En segundo lugar, la trasgresión al Convenio 169 ratificado por Chile el 2009 que obliga a los Estados a realizar las consultas sobre los proyectos de desarrollo que se encuentren en territorios indígenas. Ninguna de estas adjudicaciones había pasado por un proceso de consulta, muchos menos por la evaluación ambiental exigida por ley. El mapa geotérmico que emerge de estas adjudicaciones entre el 2009 y el 2010, significaba la privatización de este recurso nuevamente en manos de empresas en su mayoría transnacionales. Si hasta ahora los cálculos técnicos sobre la recuperación natural de la cuenca del salar habían sido el argumento principal de defensa de los organismos públicos sobre que el salar no desaparecería; esta vez, y al decir del propio encargado de la Dirección General de Aguas de la región de Antofagasta, la geotermia ponía en peligro directo la disponibilidad de agua responsable de nutrir la cuenca. ${ }^{10}$ Finalmente, la tesis de las comunidades que detrás de la geotermia estaban las mineras se confirmaba: varias de las adjudicaciones caían en manos de empresas mineras: Antofagasta Minerals y Zaldívar, ambas controladas hoy por el grupo económico de la familia Luksic. Las comunidades esta vez empapelaron los ministerios de Energía y Economía con acciones judiciales dirigidas directamente al no cumplimiento de las legislaciones indígenas y ambientales nacionales $\mathrm{e}$ internacionales aprobadas por Chile. Estas adjudicaciones lograron detenerse, no obstante las empresas involucradas siguieron de manera silenciosa -al modo de la industria del litio- visitando comunidades, presionando a dirigentes, ofreciendo perspectivas laborales, etcétera. Hasta ahora sin logros mayores, las comunidades del salar continúan dando la pelea, negocian y entran en conflicto, legitiman su lugar y protagonismo territorial, así como su posibilidad de controlar sus recursos también como bienes económicos transables.

10 Com. pers., entrevista A.B, DGA, Antofagasta, mayo de 2013. 
Estas tensiones luego de un período de casi 3 años intentaron ser restituidas y equilibradas a través de nuevas acciones de responsabilidad y nuevos convenios entre mineras y comunidades. En ese contexto y posterior a estos conflictos, las limpia de canales se configuraron en un espacio de resignificación en las relaciones entre las comunidades, el Estado y las mineras. Con trayectorias diversas, las comunidades de Camar y Peine buscaron en estos espacios rituales, legitimar sus derechos territoriales y culturales y desde allí, redibujar sus relaciones con el Estado y las corporaciones mineras que habían sufrido un importante confrontación en el período post Pampa Colorada y Defensa del Tatio.

\section{* LA limpia de CANAles en CAMAR Y Peine: ARTI- CULACIÓN DE DERECHOS, TERRITORIO Y AGUAS}

El Talatur o limpia de canales ${ }^{11}$ como es conocido entre las comunidades atacameñas del salar de Atacama, está estructurado en tres partes fundamentalmente: la preparación de la limpia y que considera su organización por parte de los dirigentes y realizadores de costumbres tanto del trabajo como del ritual (distribución del trabajo, participación de los miembros, compra de alimentos y bebidas para los días de trabajo, obtención de los elementos para las ofrendas, etc.). Luego la actividad misma que dura de 2 a 3 días en las comunidades de Camar y Peine y que se inicia con un pago a la tierra efectuado por el yatiri o realizador de costumbres de la comunidad. Una tercera, que representa los rituales de cierre y de alguna forma una evaluación de la comunidad y sus miembros: lo esperable respecto del agua para ese año (lluvias o escasez), pérdidas de miembros y las multas para quienes no cumplieron con sus compromisos. También evalúan la participación de los actores externos que han intervenido y contribuido con recursos para la actividad. Entre ellas cuentan los recursos de las mineras que han ofrecido algún tipo de cooperación.

Al igual como lo recoge el único texto escrito existente y recopilado por Grete Mostny en 1950, la actividad se inicia invocando las nacientes de donde proviene el agua que alimenta a la comunidad. Pese a que se tiene el registro de la desaparición temprana de la lengua kunza (fi-

11 Algunos de los escasos trabajos sobre la limpia de canales en la región atacameña pueden verse en referencias (Kalazich 2013; Castro, V. y V. Varela 1994; Matus 1993 y Serracino 1985). nes del siglo XIX comienzos del XX), el Talatur es hoy el único ritual vigente en el que todavía es posible escuchar expresiones vivas de ella. En su primera frase, la palabra puri que significa agua en kunza representa la reiteración necesaria: Wilti puri yuyo sai, Quepe puri pachata, Awai awai awai, Solar puri yuyo talu sai, Tami puri pachata, Awai awai awai (Mostny 1954: 162-163). Mostny publica este texto del talatur en su libro Peine: un pueblo atacameño a mediados del siglo pasado, en un período de consolidación de este territorio en el imaginario nacional a través de políticas desarrollistas que Chile dirigió hacia estas regiones fronterizas y que fomentaron un masivo proceso de migración hacia los enclaves mineros de Calama y en menor medida, Antofagasta. El texto en su inicio, junto con enunciar los lugares de donde proviene al agua -vertientes, ojos, rocas-, nombra otros elementos relacionados como son los cerros tutelares y protectores; todos ellos vivientes, acompañantes, rectores del acontecer diario en las tareas siempre impredecibles de la tierra y los animales. Hacia el final del texto, las oraciones se dirigen a estimular la fecundidad de la actividad de las siembras de maíz y la papa, productos principales en las economías de Socaire y Peine.

La comunidad de Camar se encuentra a $39 \mathrm{~km}$ de la localidad de San Pedro de Atacama y a unos aproximadamente 2 mil metros de altura. Tiene una población de 60 personas permanentes, la cual crece para festividades y vacaciones luego del término de la actividad escolar. Camar se encuentra al centro del salar, muy cerca de la Reserva Nacional Los Flamencos y al lado de la actividad extractiva de la empresa SQM (ex Soquimich). Con la política indígena de los años noventa, las otras comunidades habían logrado insertarse de diversas maneras a la actividad económica de la minería y el turismo, a su vez habían avanzado en adquirir algunos de sus derechos territoriales demandados y algunas incluso, consiguieron inscribir parte de sus aguas bajo la forma de derechos de aguas comunitarias. No obstante, Camar había quedado marginada de este proceso, estigmatizada por las autoridades como resistente al desarrollo y sin poder de interlocución con las empresas existentes en su territorio. A diferencia de otras comunidades que habían alcanzado legitimidad y espacio por negociar con la minería, como en el caso de Peine, u otras por oponerse, como Socaire, Camar inicia un proceso para recuperar lugares de pastoreo tradicionales. Paralelamente, tomando conocimiento 
de que las inscripciones de tierras estaban aún a nombre de la CONADI y no habían sido traspasadas a la comunidad, es que comienzan a acelerar el proceso con este organismo e inician gestiones directas con SQM, principal minera presente en la comunidad y cuya actividad extractiva de litio se traduce en cinco perforaciones que colindan con el territorio demandado por Camar. A su vez, y luego de una visita en terreno al sitio de Quelana, ancestralmente utilizado para el pastoreo y extracción de sales de la comunidad, próxima al sector Quelana en la Reserva Nacional Los Flamencos y vecinos de las operaciones extractivas de SQM, observan el acelerado deterioro del lugar, responsabilizando al Estado y las mineras sobre este impacto. Es a partir de este hecho que la comunidad inicia una estrategia de acercamiento directo con la minera, a fin de establecer relaciones y conseguir avances concretos luego de una crítica por la falta de respuestas a sus demandas por parte de las instituciones del Estado.

La limpia de canales en la comunidad de Camar se realiza en el mes de septiembre, aprovechando los días libres de las Fiestas Patrias y la cercanía con el inicio del año agrícola el 1 de agosto, día de la pachamama. Esto principalmente porque es una oportunidad de reunir a toda la comunidad que durante el año circula entre el poblado, el centro turístico y administrativo en San Pedro de Atacama, el sector del Alto Loa y la ciudad de Calama. La actividad se inicia en la mañana con la toma de asistencia y donde cada familia y según la cantidad de terrenos presenta a sus peones, quienes realizarán el trabajo durante los dos días que dura la actividad. Los "propietarios" que son nombrados son aquellos que hacen y han hecho uso de la tierra en términos agrícolas, vale decir no efectiva ni exclusivamente quienes tienen inscritos terrenos formalmente. Esto no se produce exento de discusiones y debates entre comuneros que buscan legitimar su rol dentro de la comunidad y su poder para decidir sobre asuntos como el riego, la tierra y otras actividades. Se impone un sistema de régimen de propiedad basado en el uso efectivo y permanente de la tierra y el agua para la producción de la unidad doméstica. Quedan afuera resquicios legales o argumentos de derecho entre quienes inscribieron o no sus tierras, y de esta forma se constituye en un espacio donde los miembros de la comunidad afirman su pertenencia en relación con la tierra y el uso del agua para la siembra. Una vez clarificados los roles, el tipo de trabajo y los tiempos distribuidos entre hom-

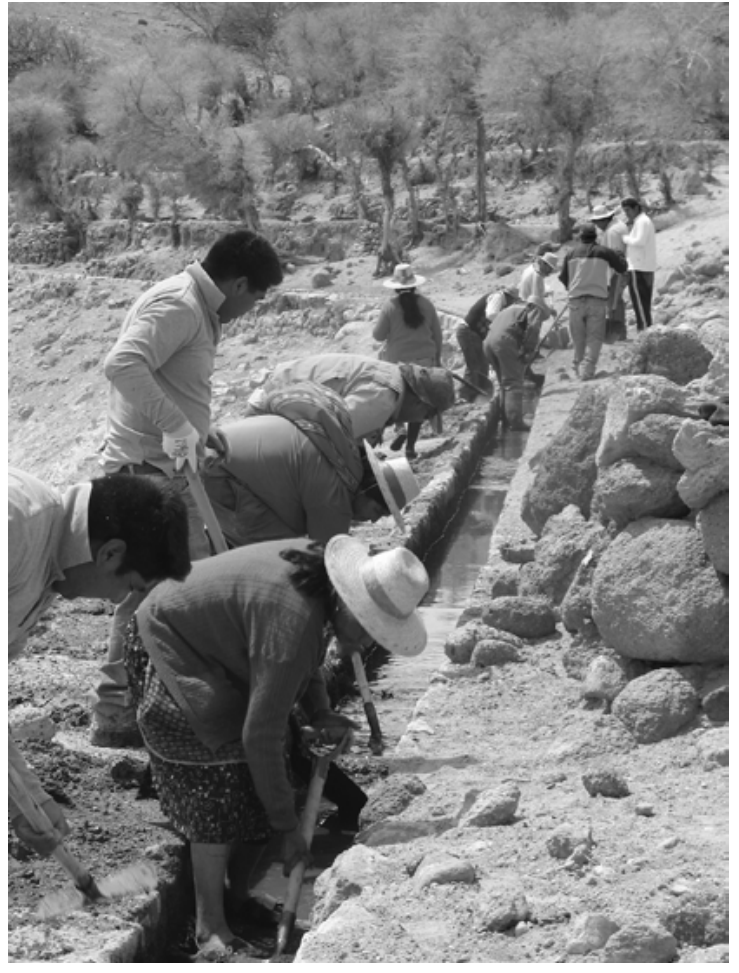

Figura 3.

bres y mujeres por igual, la comunidad se dirige al lugar de la ofrenda. Ésta se realiza donde el canal termina, por lo cual se constituye el lugar donde se da inicio a la limpia de canales luego de celebrar el pago a la tierra. Como bien señala su nombre, el objetivo de este ritual es "limpiar el canal" que provee los cultivos de la comunidad, hasta llegar al tranque acumulador que nutre y permite contar con el agua en tiempos de escasez (Figura 3). El pago a la tierra, ceremonia andina central, es celebrado por un yatiri, encargado de realizar este tipo de rituales y responsable de mantener la tradición que asegurará una relación buena con sus antepasados, la tierra o pachamama y los mallkus protectores identificados con los cerros tutelares. En este caso, el volcán Láscar es el mallku protector y hacia el cual se dirigen las invocaciones y las diversas ofrendas que entregan para agradecer a la tierra y pedirle que reciba la limpia. Hoy en día, éste es dirigido por uno de los realizadores de costumbre, quien abre la actividad pidiendo a la tierra que reciba este ritual como ofrenda de la comunidad y durante el año retribuya con una buena cosecha y un crecido ganado. El realizador de costumbre le pide que inicie el ritual al más antiguo del pueblo y padre de una de las familias que dieron origen al actual poblado. Él a su vez, fue durante muchos 
años el cantal o encargado del Talatur en la comunidad de Socaire, dando cuenta de las redes de parentesco entre estas comunidades del sur del salar de Atacama. Una vez terminado el ritual del pago y con el permiso de la tierra se da inicio a las actividades de la limpia en medio de permanentes interpelaciones a las ausencias durante el año, las acciones incumplidas con la unidad doméstica y la comunidad, así como las exigencias nuevas que significará continuar confirmando su pertenencia a ella. Con breves descansos y comidas de cierre, los miembros de la comunidad reafirman su relación histórica y territorial, así como dan señales de su fuerza y poder en un contexto de presiones por el agua de parte de las empresas mineras presentes en la región del salar. En medio del trabajo exigente, la alegría y el permanente coqueo de hojas, la actividad muestra la capacidad organizativa y las obligaciones comunitarias que siguen rigiendo a los miembros, pese a estar en lugares distantes, trabajando en mineras o bien establecidos en Calama. Durante el trabajo de la limpia, los miembros permanentemente hacen memoria de los cambios del pueblo en las actividades tradicionales y los rituales. Como nos cuenta un dirigente de la comunidad de Camar, la limpia de canales ha ocupado y sigue ocupando un lugar central en la ritualidad atacameña; más aún, en el último período debido a las presiones de minería sobre el territorio y sus recursos:

...significaba cantarle a la tierra, cantarle a los cerros, cantarle a la vertiente, al agua, se refería a todo, un agradecimiento... yo creo que la limpia nunca va a desaparecer, es una gran conservación a los mismos terrenos, a las mismas terrazas que tiene la gente, así que nunca va a desaparecer... afirma la comunidady afirma el terreno que tiene, porque cuando no trabaja va perdiendo la merced de agua que tiene su terreno... aunque tiene derechos tiene que pagar igual nomás para retornar el agua a su predio... está llegando más agua porque estamos arreglando... estamos haciendo un tranque súper grande, para traer agua desde la vertiente y eso va a ser para riego... antes se hacía mucho mejor... la gente era más unida, había más gente de edad... más responsable, era mucho mejor, era más bonito que ahora... ahora mucha gente joven que no agarra mucho, a veces agarra... hasta el año noventa y tanto... ahí cuando desaparecieron los viejitos... ahí cuando los niños empezaron a trabajar, a tener su plata, empezó a ser una cosa más individual, hacer ellos lo que querían, ahí como que se rebajó pero ahora se retomó de nuevo... ese sentido que siempre lo ha tenido, la limpia de canales, de mantener los canales limpios, de que el agua avance más en el riego, en la superficie. Esa es la intención de todos los años de la gente... este año se hizo mucho mejor. Se compartieron comida por tres días, fue bonito. La gente se está incentivando... la gente no comparte con la minería... yo tuve un balance, una conversación con la gente, fijese aunque litio [refiriéndose a la empresa Rockwood Lithium] está haciendo una buena oferta... y si usted le habla de SQM se paran y se van todos... le tienen más fe al litio que a SQM... solo quieren que se vaya (dirigente de Camar, extracto de entrevista, enero 2013).

En medio de la actividad, observamos que la mayoría de los hombres de Camar utiliza ropa de mineras en las cuales han trabajado: "Escondida", "Zaldívar", "SQM" serán marcas inscritas en las ropas de trabajo de los hombres y que se observarán durante el trayecto hacia el tranque, dando cuenta de la presencia activa y permanente de esta industria en la vida de las comunidades del salar. No exento de esto, en medio del trabajo los discursos sobre el desarrollo, el futuro y la comunidad muestran que indefectiblemente se deben pensar y organizar en torno a las relaciones con la minería. Relaciones que aunque desiguales, deben desarrollarse, mejorarse, y resignificarse. Luego de recorrer unos $4 \mathrm{~km}$ "limpiando" y llegando al tranque, comienzan los reclamos al presidente por parte de los peones que desertaron, los que no cumplieron del todo con sus obligaciones y por lo tanto, los cuestionamientos a sus derechos sobre el agua. La limpia se cierra con una comida, para la cual un aporte fue entregado por la minera SQM, que se compromete a participar más directamente con la comunidad luego de tensas relaciones en los últimos años. La limpia ha cumplido con volver a constituir a la comunidad, a definir los roles de sus dirigentes, de los comuneros, del Estado y las mineras. Quedan aspectos pendientes, deudas no cerradas que constituirán el centro de las actividades siguientes, todas ellas encauzadas en alcanzar el equilibrio con la tierra y sus antepasados, otorgándole nuevos significados a los usos del agua y la participación de la comunidad en la comunidad política mayor.

En Peine, y muy similar a lo descrito antes para Camar, los miembros de la comunidad que viven en otras ciudades de la región por razones de trabajo o educación (principalmente Calama, Antofagasta y San Pedro de Atacama) aprovechan los eventos y fiestas tales como la limpia de canales para viajar al pueblo y cumplir con sus obligaciones rituales, pasar un tiempo con la familia 
y evitar acusaciones (ya sean en broma o serias) de otros peineños de haber abandonado sus huertos heredados y las tierras ancestrales. La limpia de canales tiene lugar durante la segunda semana de octubre, pero se organiza mediante un proceso consensuado de toma de decisiones en asamblea comunitaria, una o dos semanas antes de la tarea. En Peine, se consideran tres días para llevar a cabo el trabajo, le sigue un día de descanso y luego dos días más para la limpieza de los canales de Tilomonte, un oasis agrícola a unos $15 \mathrm{~km}$, también cultivado por peineños. Las decisiones sobre los trabajos de la limpia son lideradas por un peineño de alrededor de 70 años, con los conocimientos tanto administrativos como rituales sobre cómo debe hacerse la limpia, el trabajo previo y durante la limpia, el estatus de los títulos de dominio de los terrenos irrigados por los canales, y otros roles importantes, tales como la preparación del almuerzo para el tercer día. Durante la asamblea de la comunidad, se deciden los "capitanes", que son los encargados del trabajo comunitario. Uno de ellos (que puede ser mujer) lidera el grupo de trabajo, ayudando a los comuneros que deben ubicarse en hilera siguiendo el canal, y el otro va a la retaguardia, haciendo sonar su clarín. Los capitanes llevan instrumentos tradicionales y los tocan para "arrear" a los trabajadores, los que responden con bromas sobre la pereza de los capitanes, o en mofa también les arrojan barro o malezas mientras trabajan. Las bromas y la risa caracterizan el trabajo, las cuales se interrumpen con ofrendas rituales al agua, los antepasados, a los cerros tutelares y al agua en sí.

La tarea de la limpia de canales de Peine comienza el primer día en la base de los canales, donde en los meses en que no se riega, desaguan hacia la playa del salar, y continúa hacia arriba para finalizar en el nacimiento de las vertientes que alimentan el sistema de irrigación. En cada sección de los canales el capitán llama a los propietarios con tierras en ese sector, y un trabajador toma su lugar en la fila siguiendo el canal. Lo más usual es que salga un miembro de la familia o un peón en lugar del anciano o fallecido propietario mencionado en la lista, y si no sale nadie, el capitán asigna una tarea o multa para la familia. Si bien la limpia de canales es una ceremonia y trabajo comunitario atacameño, también se encuentran presentes personas no-atacameñas; entre ellas antropólogos, y peones del sur de Chile, de Bolivia o de otros lugares del norte que viven en Peine y trabajan en las plantas de li- tio del salar o como trabajadores contratistas para SQM. Destaca la participación en el Talatur de un trabajador ya retirado de la planta de litio cercana a Peine, que ha vivido en el pueblo por algunas décadas y está casado con una peineña. De distintas maneras, el trabajo de cada afuerino está conectado por relaciones específicas dentro del pueblo. Cada trabajador presente lleva las herramientas apropiadas en representación de un propietario peineño o en representación de ellos mismos como propietarios, legitimando su derecho a utilizar los canales para alimentar sus huertos y tierras, y así sostener a su familia y pequeño rebaño. Al comienzo del tercer día de trabajo en Peine, comienza la limpieza del tranque del sector medio de los predios agrícolas. Un grupo de hombres se reúne en torno a un listado, calculando la porción del tranque que cada propietario debe limpiar según el número de predios que riegan en ese sector. El capitán dice las medidas en voz alta y dos hombres dentro del tranque (supervisados por el segundo capitán) demarcan el fondo lodoso estirando una cuerda y dibujando una línea con la pala. Una vez tomadas las medidas, el capitán llama a los trabajadores a entrar al tranque y comenzar la dura tarea de limpiar el lodo y musgo de su base, mientras la mayoría de las mujeres trabajadoras cortan el pasto y maleza de la ribera con sus palas amontonando las piedras en la orilla. En la limpia de canales del 2011, cuando los capitanes declararon el tranque limpio, uno de los comuneros habló frente a los trabajadores de la importancia de mantener el ritual, invitando a cada participante presente a beber de un pequeño jarro de aloja (bebida ceremonial hecha de algarrobo, árbol de la zona).

Una vez que el grupo de trabajadores logra llegar al nacimiento o vertiente principal del pueblo, se reúnen arriba con las mujeres mayores que pasaron el día preparando el almuerzo para los trabajadores y niños, y con el cantal y los aprendices del cantal o líderes rituales, quienes mientras tanto han comenzado el ritual del Talatur. Un pequeño grupo de hombres de mediana edad, así como algunas mujeres jóvenes que han estado aprendiendo las responsabilidades y cantos asociados con este ritual en años recientes, se encargan de reunir las ofrendas como plumas de flamenco de los hogares (ofreciéndolas junto con los otros materiales del ritual) y de apoyar el cantal en ejecutar una ceremonia en el nacimiento. Tras esto y una vez completada la limpia de los canales, se lleva a cabo una ceremonia de cierre más pública, que tiene lugar 
en la piscina que se encuentra en la parte alta del pueblo, a la cual fluye directamente el agua del nacimiento. En el 2011, parte del equipo comunitario de Minera Escondida, pidió autorización a la comunidad para participar del último día de la limpia. La ceremonia del Talatur se inicia con los cantales de espalda a la piscina y de frente a los cerros y al grupo de trabajadores, usando una mezcla que incluye aloja y granos molidos de la cosecha previa. Con la aloja se bendice a los presentes mientras también se ofrenda la mezcla a los cerros o mallkus protectores, nombrando a cada uno de los que se encuentran en el territorio peineño. De manera similar a lo que se describe para Camar, los sacrificios ofrendados por la comunidad a los cerros y al agua como espíritu, son para pedir buenas lluvias, una cosecha plena y rebaños de animales fuertes. Los trabajadores, de pie, miran hacia el salar mientras son salpicados con la mezcla, y luego forman un círculo alrededor de los cantales para comenzar el canto del Talatur, bastante similar a como aparece en el trabajo de Mostny (1954). Una vez que se ha completado el Talatur propiamente tal, mujeres y hombres jóvenes se tiran juntos a la piscina, un jugueteo e inmersión que vincula directamente sus cuerpos con los deseos de fertilidad de sus cultivos y animales para el año venidero (ver también a Kalazich 2013: 233).

Los peineños en general, acogen favorablemente las oportunidades que da la industria minera en términos de empleo, así también como medio para mejorar los problemas de infraestructura. La profundidad y el tenor de las relaciones que la comunidad de Peine mantiene con las empresas mineras es variada. En los últimos años, ha buscado formalizar sus relaciones con distintas operaciones extractivas que tienen lugar dentro de su territorio. Peine tiene acuerdos contractuales sobre la provisión de infraestructura para el desarrollo comunitario y beneficios económicos con BHP Billiton, y recientemente suscribió un acuerdo importante con Rockwood Lithium. La comunidad ha buscado llegar a tales acuerdos en lo que entienden como una ausencia del Estado en las regulaciones de la actividad extractiva de la industria minera y la baja inversión gubernamental en infraestructura para su pueblo. Dado que tienen poca capacidad de controlar lo que ocurre en su territorio en vista de los capitales transnacionales y la voluntad política orientada a la extracción, estos acuerdos representan un esfuerzo para tener más cercanía con las empresas mineras.

\section{* A MOdO DE CIERRE}

Luego de casi cuatro décadas de neoliberalismo en Chile, rituales del agua como el Talatur o la limpia de canales en el contexto del salar de Atacama, se constituye en un hecho etnográfico relevante donde observar las estrategias de relación y confrontación, así como de identificación y reinterpretación de la identidad en un marco de presiones por los recursos naturales del salar, en particular el agua y con ella, el territorio. En este sentido, comprendemos el papel del agua en este ritual, no solo como un elemento cultural asociado a la cosmovisión, sino también como un recurso económico que las comunidades pretenden recuperar y administrar, mostrando la otra cara de la misma moneda: el interés en participar también de los beneficios de este recurso en tanto un bien económico intercambiable. El agua se presenta, así, como un reflector prismático de otros significados en los cuales confluyen sentidos, prácticas y rituales, como un elemento tanto de la cultura como del mercado, simultáneamente (Babidge 2015). De allí que el agua sea demandada hoy como un elemento fundamental para la actividad económica y cultural de las comunidades atacameñas, y al mismo tiempo como un elemento de transacción rentable que desean controlar en tanto habitantes originarios de este territorio.

Si bien la limpieza anual de los canales de regadío funciona resolviendo necesidades materiales de mantención de la infraestructura agrícola del pueblo, puede también entenderse en términos económicos como los propietarios de tierras que ejercen sus derechos a y responsabilidades sobre el agua para el riego. La ejecución de estos derechos y responsabilidades sostienen la práctica agrícola tradicional y la tenencia hereditaria de la tierra, así como la membresía a la comunidad de las personas pertenecientes a las comunidades del salar. Para los peineños y cameños, las costumbres y actividades culturales se sostienen a la par de sus vidas en otros pueblos de la región, o en largas horas trabajando para las minas y viviendo en la localidad; o en el caso de las mujeres, trabajando largas horas en servicios de alojamiento o alimentación prestados a la industria minera. Más allá de este punto, la participación en el Talatur articula un sentido de pertenencia personal, familiar y comunitaria en términos de una propiedad y responsabilidad territorial de un orden cosmológico mayor, donde las aguas se constituyen un 
marcador de relaciones sociales y culturales históricas tanto intracomunitarias (con las otras comunidades) como extracomunitarias (con las mineras y el Estado).

En este contexto de disputas por el agua en el salar de Atacama, la limpia de canales en tanto actividad comunitaria, se configura hoy para las comunidades atacameñas del sur del salar, en un ritual relevante de afirmación social y política en un contexto de la neoliberalización de la naturaleza. En particular a través de un mercado de aguas liberalizado pero también condicionado por los contextos culturales y rituales de las comunidades donde se desarrollan actividades extractivas mineras. El Talatur se constituye, a nuestro entender, en un ritual del agua que contesta el imaginario exclusivamente mercantilista sobre el territorio, desafiando su significado económico (como recurso) e incorporando sus dimensiones curativas y simbólicas. A su vez, es el espacio donde con-fluyen valores, conocimientos y políticas heterogéneas que no necesariamente se excluyen sino por el contrario se condensan en complejas relaciones y negociaciones.

En este marco de tensiones y relaciones entre comunidades y mineras, las estrategias de movilización y judicialización son incorporadas en la competencia de lógicas culturales fundadas en el intercambio. Las empresas, con todo su poder simbólico y material, se ven igualmente presionadas a ingresar y participar de diversas formas y acciones de responsabilidad social y fundaciones, como también en la limpia de canales, donde cooperan y sellan acuerdos a través de convenios que las comunidades entienden como necesarios para su desarrollo y permanencia en sus territorios.
La ritualidad, en ese sentido, se hace parte del extractivismo impuesto. El extractivismo es subvertido en la lógica de intercambio y reciprocidad así como también en la lógica del mercado que comunidades y empresas tienen en el salar, por su relación histórica con el capitalismo minero cuprífero y más recientemente la minería no metálica del litio. La revitalización más reciente de la ritualidad de la limpia de canales en las comunidades atacameñas del sur del salar de Atacama, se presenta entonces como una estrategia de legitimación cultural, política y económica, que incorpora los lenguajes e instrumentos jurídicos y técnicos al amparo de una indigenidad que se articula con el proceso de privatización creciente de las aguas subterráneas en la región del salar de Atacama. En este extractivismo minero, el rol del Estado chileno colabora en otorgar las garantías de crecimiento y expansión de la actividad industrial, invibilizando y minimizando los riesgos para vida de las comunidades atacameñas del salar.

\section{* Agradecimientos}

Nuestros agradecimientos a los evaluadores que realizaron enriquecedoras críticas al primer manuscrito, y en particular, a los miembros de las comunidades atacameñas de Camar y Peine, quienes permitieron realizar nuestros trabajos de campo en los períodos 2010-2015. Agradecemos también a las instituciones que apoyaron las investigaciones de las cuales este artículo es uno de sus frutos: el proyecto FONDECYT 8120062 y el Instituto de Ciencias Sociales de la Universidad de Valparaíso, así como el Consejo Australiano de Investigaciones (Australian Research Council, DP\#1094069) y la Escuela de Ciencias Sociales de la Universidad de Queensland.

\section{$\diamond$ Referencias citadas}

ALDUNATE, C. 1985. La desecación de las vegas de Turi. Chungara 14: 135-140.

BABIDGE, S. 2013. "Socios": the contested morality of "partnerships" in indigenous community-mining company relations, northern Chile. Journal of Latin American and Caribbean Anthropology 18 (2): 274-293.

BABIDGE, S. 2015. Contested value and an ethics of resources: water, mining and indigenous people in the Atacama Desert, Chile. The Australian Journal of Anthropology, (online first). doi: 10.1111/ taja.12139
BARROS, A. 2009. Water rights and irrigation for indigenous communities in the chilean altiplano. Mountain Research Initiative Newsletter 3: 10-13.

BOLADOS, P. 2014a. Los conflictos etnoambientales de "Pampa Colorada" y "el Tatio" en el salar de Atacama, norte de Chile. Procesos étnicos en un contexto minero y turístico transnacional. Estudios Atacameños Arqueología y Antropología Surandinas 48: 229-248.

BOLADOS, P. 2014b. Procesos tras-nacionales en el salar de Atacama - norte de Chile. Los impactos de la minería y el turismo en las comunidades indígenas atacameñas. Intersecciones en Antropología 15: 431-443. 
BUDDS, J. 2013. Water, power, and the production of neoliberalism in Chile, 1973-2005. Environment and Planning D: Society and Space 31:301-318.

CASTRO, V. y V. VARELA. 1994. Ceremonias de tierra y agua. Ritos milenarios andinos. Fondart, Santiago.

CARRASCO, A. 2016. A biography of water in Atacama, Chile: two indigenous community responses to mining extractive encroachments. Journal of Latin American and Caribbean Anthropology (en prensa).

COMISIÓN CHILENA DEL COBRE. 2010. Anuario de estadísticas del cobre y otros minerales. Yearbook: Copper and other Mineral statistics. Cochilco, Santiago. http://www.cochilco.cl/ productos/descarga/anuarios/anuarioz 2010.pdf (1 enero 2013).

CONGRESO NACIONAL DE LA REPÚBLICA DE CHILE. 1993. Ley 19.523. Sobre protección, fomento y desarrollo de los indígenas.

CONGRESO NACIONAL DE LA REPÚBLICA DE CHILE. 1994. Ley 19.300. Bases Generales del Medio Ambiente.

CONGRESO NACIONAL DE LA REPÚBLICA DE CHILE. 2000. Ley 19.657. Ley sobre Concesiones Geotérmicas.

CONGRESO NACIONAL DE LA REPÚBLICA DE CHILE. 2001. Reglamento del Sistema de Evaluación de Impacto Ambiental.

CUADRA, M. 2000. Teoría y práctica de los derechos ancestrales de agua de las comunidades atacameñas. Estudios Atacameños 19: 93-112.

DESCOLA, P. y G. PALSSON. 2001. (Coords.) Naturaleza y Sociedad. Perspectivas Antropológicas. Siglo XXI editores, México.

DIRECCIÓN GENERAL DE AGUAS. 2012. Evaluación de los Recursos Hídricos Subterráneos del Acuífero del Salar de Atacama. Informe técnico. Departamento de Administración de Recursos Hídricos. SDT nº 324. Ministerio de Obras Públicas.

GUDYNAS, E. 2012. Estado compensador y nuevos extractivismos. Las ambivalencias del progresismo sudamericano. Nueva Sociedad 237: 128-146.

HOURI, A. 2012. Desenvolvimento, reconhecimento de direitos e conflitos territoriais (org). ABA Publicaçoes, Brasilia.

KALAZICH, M. F. 2013 Cultural meanings and values of the past. A participatory approach to archaeology in the Atacameno Community of Peine, Chile. Doctoral thesis, Institute of Archaeology, University College London.
MATUS, A. M. 1993. El ceremonial de la limpia de canales en Caspana. Revista Chilena de Antropología 12: 65-86

MAUSS, M. 1990. The gift: the form and reason for exchange in archaic societies. Roudleage, London.

MERLINSKY, G. 2013. Cartografias del conflicto ambiental en Argentina (Comp.). Ediciones CICCUS, Buenos Aires.

MOSTNY, G. 1954. Peine: un pueblo atacameño. Instituto de Geografía, Facultad de Humanidades de la Universidad de Chile, Santiago.

ORLOVE, B., y CATON, S. 2010. Water Sustentability: Anthropological Approaches and Prospects. Annual Review Anthropology 39: 401-415.

PRIETO, M. 2014. Privatizing water and articulating indigeneity: the chilean water reforms and the atacameño people (Likan Antai). A Dissertation Submitted to the Faculty of the School of Geography and Development, University of Arizona. In Partial Fulfillment of the Requirements for the Degree of Doctor of Philosophy.

SAWYER, S. y E. T. GÓMEZ. 2012. The politics of resource extraction: indigenous peoples, multinational corporations and the state. Palgrave Macmillan, London.

SERRACINO, G. 1985. Creencias, organización social y económica en Caspana Indígena. La limpia de canales. Actas I Congreso Chileno de Antropología, pp. 398-410.

SERNAGEOMIN, 2010. Anuario de la Minería de Chile, http:// www.sernageomin.cl/pdf/mineria/anuario_2010.pdf (1 enero 2013), Santiago.

SILVA, E. 1996. Democracy, market economics, and environmental policy in Chile. Journal of interamerican studies and world affairs 38 (4): 1-33.

STRANG, V. 2004. The meaning of water. Berg, Oxford.

SVAMPA, M. y M. ANTONELLI. 2010. Minería trasnacional, narrativas del desarrollo y resistencias sociales. Biblos, Buenos Aires.

TECKLIN D., C. BAUER y M. PRIETO. 2011. Making environmental law for the market: the emergence, character and implications of Chile's environmental regime. Environmental Politics 20 (6): 879-898.

YÁÑEZ, N. y R. MOLINA. 2011. Las aguas indigenas. LOM, Santiago.

YÁÑEZ, N. y R. MOLINA. 2008. La gran minería y los derechos indigenas en el norte de Chile. LOM, Santiago. 